\title{
The effect of sex of last child on short birth interval practice: the case of northern Ethiopian pregnant women
}

\author{
Amare Genetu Ejigu ${ }^{1 \dagger}$, Ayenew Engida Yismaw ${ }^{2}$ and Miteku Andualem Limenih ${ }^{2^{*}+}$
}

\begin{abstract}
Objective: Improving short birth interval practice is a key strategy to reduce maternal mortality, neonatal mortality, adverse pregnancy outcomes, high fertility rate and undermining economic development efforts. However, there were limited evidences on short birth interval practice and its determinant factors in Ethiopia. This study aimed to determine the prevalence of short birth interval practice and associated factors among pregnant women. Institutional based cross-sectional study was conducted among 418 pregnant mothers using stratified sampling technique. Multivariable logistic regression analysis was performed at the level of significance of $P$-value $<0.05$.

Result: Short birth interval practice was found to be $40.9 \%$. Child death ( $A O R=3.60,95 \% \mathrm{Cl} 1.35,9.59$ ), female child $(A O R=2.03,95 \% \mathrm{Cl} 1.12,3.67)$, younger maternal age $(A O R=4.23,95 \% \mathrm{Cl} 1.14,12.66)$, contraceptive non-use $(A O R=8.15,95 \% \mathrm{Cl} 4.17,15.94)$, increase duration of breastfeeding $(A O R=4.72,95 \mathrm{Cl} \% 1.10,20.60)$ and home delivery $(A O R=4.75,95 \mathrm{Cl} \% 2.30,9.79)$ were found to be significantly associated with short birth interval practice. The prevalence of short birth interval practice is high. Multi disciplinary approach through improving maternal and child health care are recommended to prevent short birth interval practice.
\end{abstract}

Keywords: Birth interval, Pregnant women, Ethiopia, Short birth interval practice

\section{Introduction}

Birth interval is the length of time between two successive live births [1]. Evidences showed that birth intervals should be spaced for three to 5 years apart to ensure maximum health benefits for mothers and newborns, which is recommended by WHO; after a live birth, the interval before attempting the next pregnancy is at least 24 months [2-4].

Globally, there were 287, 000 maternal deaths and 3.1 million neonatal deaths in 2013 and most of these occurred in south Asia and in sub-Saharan Africa [5, 6]. EDHS 2016 showed; there is high maternal mortality, 412 deaths per 100,000 live births [7] and more than $42 \%$ of

\footnotetext{
*Correspondence: mitekuandualem2017@gmail.com

${ }^{\dagger}$ Amare Genetu Ejigu and Miteku Andualem Limenih have contributed equally to this work

${ }^{2}$ Department of Midwifery, College of Medicine and Health Sciences, University of Gondar, Gondar, Ethiopia

Full list of author information is available at the end of the article
}

under-5 mortality was neonatal deaths [8]. Short birth interval increase risk of maternal mortality and adverse pregnancy outcomes (neonatal mortality, low birth weight, small fetus, and pre-term delivery) $[3,9]$.

Studies done in USA, DHS from 66 low and middleincome countries and in Bangladesh showed; neonatal, infant, child mortality and stillbirth are high when the women practice short birth interval [10-12]. Evidences showed that, birth interval less than 18 months leads to $12 \%$ neonatal death, $84.4 \%$ LBW and decrease neonatal survival [13-16].

In Ethiopia, Short birth interval affects fertility as well as neonatal, infant and Childhood mortality [17]. Promoting the length of birth interval for a minimum of two years results reduction of infant mortality by $50 \%$ and reduces fertility rate by $43 \%$ [18-20].

Beyond the health implications, close birth intervals increase population growth, makes women to be less productive and the family will invest more of their limited resources to child care [2]. 
According to researches; maternal age, level of education, marital status, residence, loss of child, sex of child, contraceptive use, breast feeding, and age of pregnancy are contributing factors $[1,21-28]$. However, the determinants of short birth interval practice are not the same across different cultures and socio-demographic status within the society. Therefore, this study aimed to assess factors affecting short birth interval practice among pregnant women in Debremarkos town governmental health institutions, Ethiopia.

\section{Main text}

\section{Study setting}

The study was conducted at Debremarkos governmental health institutions from April 1 to July 30, 2016. The town has 101,582 populations [29]. The numbers of governmental health institutions in the town were four. 10 BSc, 14 diploma Midwives and 8 diploma Nurses were providing health care services in the maternal care unit of these health institutions. The study was done using institutional based cross-sectional design on all pregnant women who had at least one live birth during ANC visit in debremarkos town governmental health institutions during the study period.

\section{Required sample size}

Single population proportion formula was used to calculate the total required sample size of the study considering the assumption of $95 \%$ confidence level, $5 \%$ margin of error, $57.6 \%(\mathrm{P})$ the proportion of short birth interval practice which is taken from previous study [24] and considering $10 \%$ of possible non response rate. This gave us the total required sample size of the study to be 418 .

\section{Sampling technique}

Systematic random sampling techniques were used to select the required sample size then through distributing the required sample size to each governmental health institution allocated in the town based on proportional number of multigravida pregnant women who had ANC visit during study period. For procedure, we used sampling interval approach. Sampling interval (K) was calculated using the summation of 4 months multigravida pregnant women who had ANC visit in all governmental health institutions, which were 920 . Then $K=N / n$, $920 / 418=2.201 \approx 2$. Every 2 nd pregnant women were interviewed. To start with the first interview we used lottery method.

\section{Operational definition}

Short birth interval: if the interval between last birth and current pregnancy expected date of delivery is $<33$ months.

\section{Data collection techniques}

The data was collected using Amharic questionnaire which is translated from English language. Before the actual data collection; pre-test was done on $5 \%$ of total sample size out of the study area which has similar socio demographic context. To collect all the required data we used four diploma midwives.

\section{Data analysis techniques}

SPSS version 20 software was used to analyze the data. Variables having P-value of $<0.20$ in bivariate analysis were entered into multiple logistic regressions for further analysis. Finally, variables with P-value $<0.05$ in multivariable logistic analysis were considered as statistically significant.

\section{Socio-demographic Characteristics of the Participants}

A total of 418 pregnant women who came for ANC follow-up in Debremarkos governmental health institutions were interviewed with a response rate of $98.3 \%$. The mean age was 30 years $(\mathrm{SD} \pm 5.14), 405$ (96.1\%) mothers were Orthodox Christians, 261 (63.5\%) mothers lived in urban area (Table 1).

\section{Child related characteristics}

Two hundred sixty-three (63.9\%) mothers had 1 or 2 alive children, 96 (23.4) had 3 or 4 alive birth and 52 (12.7\%) had $\geq 5$ alive children. One hundred fifty-one (36.7\%) and 139 (33.8\%) women had no alive male and female child respectively. Two hundred four (49.6\%) mother`s last child were male. Eighty-eight (21.4\%) mother`s last child were not alive. 385 (96.7\%) mothers had designer for more child. Among these; 236 (63.1\%) mothers needs 1 to 2 more children, 120 (32.1\%) mothers needs 3-4 more children and 18 (4.8\%) mothers needs more than 4 children. 100 women`s (24.3\%) current pregnancy was unplanned.

\section{Maternal and reproductive related characteristics}

Two hundred eighty (68.1\%) of the respondent gave their last live birth in the age group of 20-29 years. $352(85.6 \%)$ women had breastfed their last child. 242 (59\%) pregnant women had breastfed their last child for 24 months and more. 357 (86.9\%) respondents were ever used contraceptives and 257 (72\%) were used contraceptives before this pregnancy. Nearly one-third (32.4\%) of study participants gave their last live birth at home. Forty-two (10.2\%) respondents gave their last birth through cesarean Sect. 243 (59\%), 66 (16\%), 25 
Table 1 Socio-demographic characteristics of multi gravid pregnant women who had ANC follow-up in Debremarkos town governmental health institution, North West Ethiopia, $2016(n=411)$

\begin{tabular}{|c|c|c|c|}
\hline Variables & Categories & $\begin{array}{l}\text { Frequency } \\
(n=411)\end{array}$ & Percent (\%) \\
\hline \multirow[t]{2}{*}{ Residence } & Urban & 261 & 63.5 \\
\hline & Rural & 150 & 36.5 \\
\hline \multirow[t]{4}{*}{ Religion } & Orthodox & 395 & 96.1 \\
\hline & Muslim & 11 & 2.7 \\
\hline & Protestant & 4 & 1.0 \\
\hline & Catholic & 1 & 0.2 \\
\hline \multirow[t]{3}{*}{ Marital status } & Married & 401 & 97.6 \\
\hline & Widowed & 1 & 0.2 \\
\hline & Divorced & 9 & 2.2 \\
\hline \multirow[t]{3}{*}{ Educational status } & No education & 173 & 42.1 \\
\hline & Primary (1-8) & 106 & 25.8 \\
\hline & $\begin{array}{l}\text { Secondary and } \\
\text { above }\end{array}$ & 132 & 32.1 \\
\hline \multirow[t]{4}{*}{ Occupational status } & $\begin{array}{l}\text { Government } \\
\text { Employee }\end{array}$ & 71 & 17.3 \\
\hline & House wife & 253 & 61.6 \\
\hline & Merchant & 60 & 14.6 \\
\hline & Student & 27 & 6.6 \\
\hline \multirow{3}{*}{$\begin{array}{l}\text { Husband education } \\
(\mathrm{n}=401)\end{array}$} & No education & 110 & 27.4 \\
\hline & Primary (1-8) & 119 & 29.7 \\
\hline & $\begin{array}{l}\text { Secondary and } \\
\text { above }\end{array}$ & 172 & 42.9 \\
\hline \multirow[t]{4}{*}{$\begin{array}{l}\text { Husband occupation } \\
(n=401)\end{array}$} & $\begin{array}{l}\text { Government } \\
\text { Employee }\end{array}$ & 132 & 32.9 \\
\hline & Farmer & 137 & 34.2 \\
\hline & Merchant & 99 & 24.7 \\
\hline & Daily laborer & 33 & 8.2 \\
\hline \multirow[t]{4}{*}{ Ethnicity } & Amhara & 388 & 94.4 \\
\hline & Oromo & 14 & 3.4 \\
\hline & Tigre & 6 & 1.5 \\
\hline & Gurage & 3 & 0.7 \\
\hline \multirow[t]{5}{*}{ Age } & $15-24$ & 47 & 11.4 \\
\hline & $25-29$ & 151 & 36.7 \\
\hline & $30-34$ & 115 & 28.0 \\
\hline & $35-39$ & 74 & 18.0 \\
\hline & $40-49$ & 24 & 5.8 \\
\hline
\end{tabular}

(6\%) and 78 (19\%) mothers had breastfed their last child for $\geq 24,13-23,7-12$ and 1-6 months respectively.

\section{Birth interval practice}

One hundred sixty-eight (40.9\%) of the study participants had practiced short birth interval. The median duration of birth interval practice was 37 months $(S D \pm 16.7)$ (Fig. 1).
Factors associated with short birth interval practice

Sex of last child, age of the mother, survival status of last child, duration of breast feeding before conception of the current pregnancy, contraceptive use and place of birth of last child were significant factors for short birth interval practice. The odds of pregnant mothers whose last child were female were 2 times more likely to have short birth interval practice $(\mathrm{AOR}=2.03,95 \% \mathrm{CI} 1.12$, 3.67). Those pregnant women who were in the age group of 15-24 years had 4 times more likely to have short birth interval practice as compared to those who are in the age group of $25-29(\mathrm{AOR}=4.23,95 \% \mathrm{CI} 1.14,12.66)$ and women who were in the age group 35-39 years and 40-49 years had 27 and 23 times less likely to have short birth interval practice as compared to those women who were at the age of $25-29$ years $(\mathrm{AOR}=0.037,95 \%$ CI $0.004,0.37$ and AOR $=0.044,95 \%$ CI $0.003,0.62$ ) respectively. Women whose last child died were 3.6 times more likely to have short birth interval practice as compared with women whose child were alive $(\mathrm{AOR}=3.60$, $95 \%$ CI 1.35, 9.59). Women who breastfed their last child for 13-23 months were 4.7 times more likely to have short birth interval as compared to those who breastfed for $<6$ months $(\mathrm{AOR}=4.72,95 \mathrm{CI} \% 1.10,20.60)$. Mothers who were not using contraceptives between their last birth and this pregnancy had 8 times more likely to have short birth interval as compared to those women who used it $(\mathrm{AOR}=8.15,95 \% \mathrm{CI} 4.17,15.94)$. Mothers who gave their last birth at home were 4.7 times more likely to have short birth interval as compared to women who gave birth at health institution $(\mathrm{AOR}=4.75,95 \mathrm{CI} \% 2.30$, 9.79) (Table 2).

\section{Discussion}

This study revealed that short birth interval practice was found to be $40.9 \%$ (95\% CI 35.9, 46.2). This finding is in line with EDHS report, 41.5\% [1]. However, it is remarkably lower than the studies done in Tanzania (48.4\%) and Southern Ethiopia (57.6\%) [23, 24]. This might be the difference in socio demographic characteristics and study period variation. The difference in prevalence across studies might be socio demographic feature of the study participants, the time gaps between the study periods, accessibility of contraceptive methods and the difference in data collection methods $[2,14,16]$.

Pregnant mothers whose last child died were 3.6 times more likely to have short birth interval than who had live child. (AOR $=3.60,95 \%$ CI $1.35,9.59$ ). This finding is in line with studies done in northwest Ethiopia and in Bangladesh [12, 26, 27]. This might be due to sociocultural influence and lack of access for contraceptive methods. When the child dies, the woman is less likely 


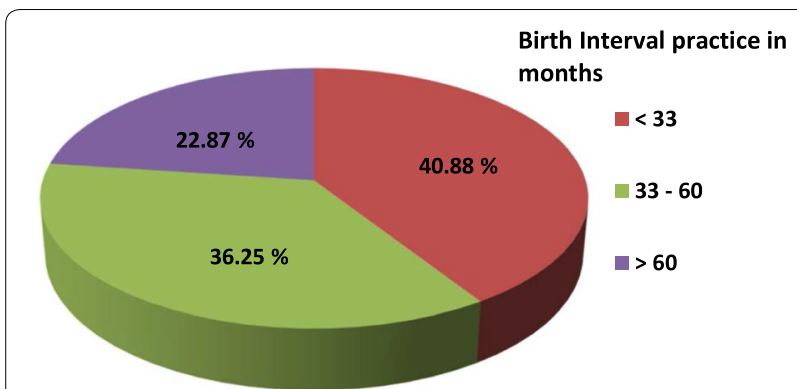

Fig. 1 Distribution of birth interval practice among pregnant women who has ANC follow-up in Debremarkos town governmental health institution, Northwest Ethiopia, $2016(n=411)$

to be protected from pregnancy, socio-cultural influences hinders to go to health institution early for contraceptive methods and there is a high need of replacing the dead child soon with new pregnancy $[2,28]$.

Women who were in the age group 15-24 were 4 times $(\mathrm{AOR}=4.23,95 \% \mathrm{CI} 1.14,12.66)$ more likely to have short birth interval compared to 25-29 age group. Women who were in the age group 35-39 and 40-49 had 27 times $(\mathrm{AOR}=037,95 \% \mathrm{CI} 0.004,0.37)$ and 23 times $(\mathrm{AOR}=0.044,95 \% \mathrm{CI} 0.003,0.62)$ less likely to have short birth interval as compared to those age 25-29. This is in consistent with the finding of EDHS, southern Ethiopia and Tanzania $[1,23,25]$. This could be older women are more likely to have the desired number of children and as the woman's age increases, fecundity decreases $[6,20]$.

Mothers who were not utilized contraceptive methods between their last birth and this pregnancy were 8 times more likely to practiced short birth interval as compared to users ( $\mathrm{AOR}=8.15,95 \% \mathrm{CI} 4.17,15.94)$. This finding is in line with study done in southern Ethiopia [24, 25]. This might be due to contraceptive utilization can delay the pregnancy. When the women use contraceptive methods, they are intentionally preventing short birth interval and its bad outcomes $[2,3]$.

Pregnant mothers whose last child were female had 2 times more likely to have short birth interval as compared to mothers who had male last child $(\mathrm{AOR}=2.03$, 95\% CI 1.12, 3.67). This finding is consistent with study done in southern Ethiopia and in Saudi Arabia [25, 28]. This might happen due to socio-cultural influence.

Those women who were breastfed for 13-23 months had 4.7 times more likely to have short birth interval as compared to those who breastfed for $<6$ months (AOR $=4.72,95 \mathrm{CI} \% 1.10,20.60)$. This finding is in line with study done in southern Ethiopia [24].

Table 2 Logistic regression showing factors on short birth interval practice among mothers who came for ANC clinic in Debremarkos governmental health institution, Ethiopia, $2016(n=411)$

\begin{tabular}{|c|c|c|c|c|c|c|}
\hline \multirow[t]{2}{*}{ Variables } & \multirow[t]{2}{*}{ Categories } & \multicolumn{2}{|c|}{ Short birth interval } & \multirow[t]{2}{*}{ COR $(95 \% \mathrm{Cl})$} & \multirow[t]{2}{*}{ AOR $(95 \% \mathrm{Cl})$} & \multirow[t]{2}{*}{ P-value } \\
\hline & & Yes & No & & & \\
\hline \multirow[t]{5}{*}{ Age of mother } & $15-24$ & 27 & 20 & $2.29(1.18,4.46)$ & $4.23(1.14,12.66)$ & 0.010 \\
\hline & $25-29$ & 56 & 95 & 1 & 1 & \\
\hline & $30-34$ & 45 & 70 & $1.09(0.66,1.79)$ & $0.73(0.34,1.55)$ & 0.408 \\
\hline & $35-39$ & 29 & 45 & $1.09(0.62,1.94)$ & $0.037(0.004,0.37)$ & 0.005 \\
\hline & $40-49$ & 11 & 13 & $1.44(0.60,3.42)$ & $0.044(0.003,0.62)$ & 0.021 \\
\hline \multirow[t]{2}{*}{ Sex of last child } & Male & 72 & 132 & 1 & 1 & \\
\hline & Female & 96 & 111 & $1.58(1.07,2.36)$ & $2.03(1.12,3.67)$ & 0.020 \\
\hline \multirow[t]{2}{*}{ Last child alive } & Yes & 118 & 206 & 1 & 1 & \\
\hline & No & 50 & 37 & $2.36(1.46,3.82)$ & $3.60(1.35,9.59)$ & 0.010 \\
\hline \multirow[t]{4}{*}{ Duration of breast feeding } & $0-6$ & 44 & 37 & 1 & 1 & \\
\hline & $7-12$ & 15 & 9 & $1.40(0.55,3.57)$ & $2.53(0.46,13.82)$ & 0.283 \\
\hline & $13-23$ & 45 & 20 & $1.89(0.95,3.75)$ & $4.72(1.10,20.60)$ & 0.039 \\
\hline & $\geq 24$ & 64 & 177 & $0.30(0.18,0.51)$ & $0.87(0.23,3.24)$ & 0.837 \\
\hline \multirow[t]{2}{*}{ Contraceptive use } & Yes & 69 & 188 & 1 & 1 & \\
\hline & No & 69 & 31 & $6.06(3.66,10.05$ & $8.15(4.17,15.94)$ & 0.000 \\
\hline \multirow[t]{2}{*}{ Last child place of delivery } & Health institution & 101 & 177 & 1 & 1 & \\
\hline & Home & 67 & 66 & $1.78(1.17,2.70)$ & $4.75(2.30,9.79)$ & 0.000 \\
\hline
\end{tabular}

$\mathrm{P}<0.05$ Statistically significantly associated with short birth interval practice in multivariable logistic regression analysis

$\mathrm{P} \geq 0.05$ is not significant in stepwise backward logistic regression. Hosmer and Lemanshow test for multivariable log reg. $=0.85$

The italicized value indicated that a statistically significant association at $95 \%$ confidence interval (Cl) that did not include 1 in the interval

$1=$ reference category 
Women might believe in, breast feeding can prevent pregnancy for long period of time and they may not use contraceptive methods which might expose them to be pregnant [22].

Mothers who gave their last birth at home were 4.75 times more likely to have short birth interval as compare to women who gave birth at health institution $(\mathrm{AOR}=4.75,95 \mathrm{CI} \% 2.30,9.79)$. This is in line with the study conducted in Tanzania and Dabat district $[23,26]$. This might be due to women who gave birth in the health facilities had more chance to have awareness through effective counseling and may receive post partum family planning methods [30].

\section{Conclusions and recommendation}

Short birth interval practice was high in the study area. Last child survival status, sex of last child, maternal age, contraceptive use, duration of breast feeding, and place of birth were determinant factors for short birth interval practice. Promoting institutional birth in collaboration with health extension workers, Creating awareness for parents through community based health education program to avoid child's sex based birth interval practice and advice on advantage of using contraceptives while breast feeding to delay pregnancy might decrease short birth interval practice.

\section{Limitation of the study}

Measuring birth interval with the women's memory and duration of breast feeding might result recall bias. Though birth interval can be explained by social and cultural issues, the questionnaire did not extend to investigate such issue in depth.

\section{Abbreviations}

AOR: Adjusted Odds Ratio; ANC: Antenatal Care; Cl: confidence interval; DHS: Demographic and Health Survey; EDHS: Ethiopia Demographic and Health Survey; LNMP: Last Normal Menstrual Period; UOG: University of Gondar; USA: United States of America; WHO: World Health Organization.

\section{Authors' contributions}

AGE: Initiated the idea, wrote the proposal, participated in designing the study, supervising data collection process, analyses the data and writing the manuscript. AEY: contributed in the designing of the methodology, analysis of the data, add important intellectual content and approval of the manuscript to be published. MAL: Involved in proposal writing, contributed in the designing of the methodology, analysis of the data, add important intellectual content and final prepared the manuscript and approval of the manuscript to be published. AGE and MAL: contributed equally to this work. All authors read and approved the final manuscript.

\section{Author details}

${ }^{1}$ Department of Midwifery, College of Health Science, Mizantepi University, Mizantepi, Ethiopia. ${ }^{2}$ Department of Midwifery, College of Medicine and Health Sciences, University of Gondar, Gondar, Ethiopia.

\section{Acknowledgements}

The authors would like to thank University of Gondar for technical support and ethical approval, study participants and Data collectors.

\section{Competing interests}

The authors declared that they have no competing interests.

\section{Availability of data and materials}

When ethics statement was obtained from the district health office, we have agreed and signed not to publish the raw data retrieved from the data of pregnant women's. However, the datasets collected and analyzed for the current study is available from the corresponding author and can be obtained on a reasonable request.

\section{Consent for publication}

Not applicable.

\section{Ethical approval and consent to participate}

Ethical clearance was obtained from internal ethical review board of university of Gondar. Written informed consent was obtained from each study participants after verbal explanation to be involved in the study. In addition both oral and written consent was obtained from both parent and study participant for one study participant whose age was less than 18. Information was given regarding the right to refuse or withdraw from the interview. Personal identifiers were not included in the written questionnaires to ensure participants' confidentiality.

\section{Funding}

The authors did not receive any funding for this study.

\section{Publisher's Note}

Springer Nature remains neutral with regard to jurisdictional claims in published maps and institutional affiliations.

Received: 27 December 2018 Accepted: 31 January 2019

Published online: 04 February 2019

References

1. Central Statistical Authority [Ethiopia]. Ethiopia Demographic and Health Survey, Addis Ababa, Ethiopia. 2011.

2. United States agency for International Development. Strengthening family planning policies and programs in developing countries. USA: USAID; 2005.

3. World Health Organization. Report of a WHO Technical Consultation on Birth Spacing Geneva. Switzerland. 2005;13-15:2007.

4. Ford K, Huffman SL, Chowdhury AK, Becker S, Allen H, Menken J, et al. Birth interval dynamics in rural Bangladesh and maternal weight. Demography. 1989;26:425-37.

5. WHO Unfpa World Bank. Trends in Maternal mortality: 1990 to 2010: Estimates developed by WHO, UNICEF, UNFPA and the World Bank. Geneva: World Health Organization; 2012.

6. Flaxman AD, Wang H, Levin-Rector A, et al. Neonatal, postneonatal, childhood, and under-5 mortality for 187 countries, 1970-2010: a systematic analysis of progress towards Millennium Development Goal 4. 2010.

7. Central Statistical Agency Addis Ababa [Ethiopia]. Ethiopia demographic and health survey 2016.

8. Federal Democratic Republic Ethiopia Ministry Health. Health Sector Development Programme Iv Annual Performance Report. EFY 2006 (2013/14).

9. Kozuki N, Leel AC, Silveira MF, et al. The associations of birth intervals with small-for gestational-age, preterm, and neonatal and infant mortality: a meta-analysis. BMC Public Health. 2013;13(Suppl 3):S3.

10. DeFranco E, Ehrlich S, Mugliaa L. Influence of interpregnancy interval on birth timing. BJOG. 2014;121:1633-41.

11. Perin J, Walker N. Potential confounding in the association between short birth intervals and increased neonatal, infant, and child mortality. Glob Health Action. 2015;8:29724. 
12. Jonge HC, Azad K, Seward N, et al. Determinants and consequences of short birth interval in rural Bangladesh: a cross sectional study. BMC Pregnancy and Childbirth. 2014;14:427.

13. Kayode GA, Ansah E, Agyepong IA, Amoakoh-Coleman M, Grobbee DE, Klipstein-Grobusch K. Individual and community determinants of neonatal mortality in Ghana: a multilevel analysis. BMC Pregnancy Childbirth. 2014;14:165.

14. Akinyemi JO, Bamgboye EA, Ayeni O. Trends in neonatal mortality in Nigeria and effects of bio-demographic and maternal characteristics. BMC Pediatrics. 2015;15:36.

15. Ezeh OK, Agho KE, Dibley MJ, Hall J, Nicholas A. Determinants of neonatal mortality in Nigeria: evidence from the 2008 demographic and health survey. BMC Public Health. 2014;14:521.

16. Ugboma H, Onyearugha C. Low birthweight delivery: prevalence and associated factors as seen at a tertiary health facility. Niger J Clin Pract. 2013;16(2):184-7.

17. Central Statistical Authority [Ethiopia]. Ethiopia Demographic and Health Survey, Addis Ababa, Ethiopia. 2005.

18. Fekadu Dadi A. Short birth intervals less than 2 years double under-one mortality in Ethiopia: evidence from a meta-analysis. Sci J Public Health. 2014;2(6):589-95.

19. Federal Democratic Republic of Ethiopia MOH. Health Sector Development Programme IV 2010/11-2014/15. 2010.

20. Taylor M. Global fertility rates declining, UN report finds. http://alj. am/9d3p. 2015.

21. Fallahzadeh H, Farajpour Z, Emam Z. Duration and determinants of birth interval in Yazd, Iran: a population study. Iran J Reprod Med. 2013;11(5):379-84.
22. Nti CA, Gadegbeku C, Sarah NA, Ofosu B, Akoto E, Agbi-Dzorkar M. Knowledge, attitude and practice of birth spacing among Ghanaian mothers: implications for maternal and child nutritional status. World Appl Sci J. 2014;31(11):1971-8.

23. Exavery A, Mrema S, Shamte A, et al. Levels and correlates of non-adherence to WHO recommended inter-birth intervals in Rufiji, Tanzania. BMC Pregnancy Childbirth. 2012;12:152.

24. Yohannes S, Wondafrash M, Abera M, Girma E. Duration and determinants of birth interval among women of child bearing age in Southern Ethiopia. BMC Pregnancy Childbirth. 2011;11:38.

25. Begna Z, Assegid S, Kassahun W, Gerbaba M. Determinants of inter birth interval among married women living in rural pastoral communities of southern Ethiopia: a case control study. BMC Pregnancy Childbirth. 2013;13:116.

26. Tessema GA, Zeleke BM, Ayele TA. Birth interval and its predictors among married women in Dabat District, Northwest Ethiopia: a retrospective follow up study. Afr J Reprod Health. 2013;17(2):39-45.

27. Chowdhury $A H$, Karim A. Patterns and differentials of birth intervals in Bangladesh. Global J Sci Front Res Interdiscip. 2013;13(2):11-24.

28. Abdel-Fattah M, Hifnawy T, El Said TI, Moharam MM, Mahmoud MA. Determinants of birth spacing among Saudi women. J Fam Commun Med. 2007;14(3):103.

29. Census. Amhara Region. https://en.wikipedia.org/wiki/Debre_Marqos. 2007.

30. Berhan Y, Berhan A. Antenatal Care as a means of increasing birth in the health facility and reducing maternal mortality: a systematic review. Ethiop J Health Sci. 2014;24:93-104.
Ready to submit your research? Choose BMC and benefit from:

- fast, convenient online submission

- thorough peer review by experienced researchers in your field

- rapid publication on acceptance

- support for research data, including large and complex data types

- gold Open Access which fosters wider collaboration and increased citations

- maximum visibility for your research: over 100M website views per year

At BMC, research is always in progress.

Learn more biomedcentral.com/submissions 